The Journal of Interlibrary Loan, Document Delivery \& Information Supply, 2002, Volume 12, Issue 4, Pages 63 77.

Print ISSN: 1072-303X Online ISSN: 1540-3572

DOI: 10.1300/J110v12n04_07

Link to publisher website.

Link to journal on publisher website.

Link to article on publisher website.

(C) 2002 The Haworth Press Inc. All rights reserved.

\title{
3D: The Paperless Document Delivery Project at the Prior Health Sciences Library
}

\section{Ruey L. Rodman}

\begin{abstract}
This article describes the investigation, pilot test, and results of implementing electronic document delivery in a paperless processing environment at The Ohio State University. The Prior Health Sciences Library Document Delivery Unit conducted a twelve-month pilot test from September 1999 to August 2000 to determine the best method for desktop document delivery and the paperless processing of requests. Participants completed a survey and provided insightful feedback on the request form and overall process. Special programming was required to implement desktop delivery and manage client requests. The result of desktop delivery was successful. The results of paperless processing were mixed. Future possibilities to complete the "paperless" environment are suggested.
\end{abstract}

\section{INTRODUCTION}

With turnaround time of article delivery as the motivating factor, the College of Medicine and Public Health (COMPH) Library Committee asked the Prior Health Sciences Library (PHSL) at The Ohio State University (OSU) to plan and implement full-text electronic delivery of requested print information. This request was not only for the faculty, staff, graduate and undergraduate students of the COMPH, but also the Colleges of Allied Medicine, Dentistry, Nursing, and Optometry, for a total primary clientele of approximately 12,500 users. The Library Committee request was made to reduce delivery time of documents so users would no longer have to wait three to five days for campus mail delivery or go to the Prior Health Sciences Library to pick up their documents. Document Delivery Unit staff knew it was technically possible to deliver documents electronically and planned a project to investigate various options, and if possible, make their internal processes "paperless." This paper describes the process to find the best method for electronic delivery of full-text information and the outcome of paperless processing.

\section{CURRENT PRACTICES}

In order to establish the framework for our investigation, it is necessary to give a brief synopsis of the current processes in the Document Delivery Unit of the PHSL. We receive 
requests for print materials by phone, fax, web form, or hand-written card. All requests are searched in the OSU Library Catalog (OSCAR). The requests are then split into two groups: available on campus or not available on campus. A $\$ 5.00$ fee is assessed for the retrieval of on campus materials and clients are advised of availability prior to retrieval. For materials not on campus or Interlibrary Loan (ILL), DOCLINE is used as our primary ordering system (95\%) and OCLC as our secondary system (5\%). We follow CONTU guidelines for fair use and royalties are paid through the Copyright Clearance Center. ILL materials are received via Ariel, US CARGO (library courier), fax, US Mail, or other national mail service. All requested materials are delivered by campus mail service or picked up at the PHSL after the client is notified by telephone.

\section{PROJECT RATIONALE}

With this new venture, motivation grew to eliminate, as much as possible, the paper pushing and paper collecting in the document delivery process. That impetus led us to develop the following objectives for the project:

1. Develop a paperless document delivery service from initial request to delivery (paperless being defined as not our paper);

2. Ensure that the adopted method for delivery complies with copyright law;

3. Create or coordinate a user education program.

Library users at OSU are very comfortable with finding or receiving full-text information through the many full-text electronic journals available as Library resources or through various web sites on the Internet. It is reasonable, therefore, that they would also request needed documents to be delivered to their workstations whether at home or in the office.

\section{LITERATURE REVIEW}

Interest in "libraries without walls" continues to grow as has published research in the digitization of information for user access twenty-four hours a day/seven days a week. A search of library, computer, and information science literature yielded many articles related to the electronic delivery of documents. For the purposes of this project the references are divided into two groups: delivery methods and copyright issues.

\section{Delivery Methods}

Electronic transmission of full-text documents has been a common process since libraries began using fax machines to send requested information to each other. The cost of the phone call, quality of transmission, and time spent packaging and delivering the article to the client have been issues libraries have dealt with since the early 1980s (Shipman et al., 1998). The rise and use of the Internet in the 1990s led to the development of delivery methods like Ariel (RLG), Relais (EBSCO), and IntelliDOC (CISTI) (Cornish, 2000). Illiad by ATLAS and DocView by 
the National Library of Medicine are also examples. In comparison to fax transmission, these systems reduce costs and, through direct document scanning, improve the quality of article transmission. Also, these systems are constantly updated and have grown from the simple transmission of documents between libraries to include modules for delivery of received documents via email to the client desktop, and also, to complete ILL management systems. The cost of purchasing any of these programs can be thousands of dollars. They may also require system specific peripherals that cost additional monies.

A growing trend in the delivery of documents is the use of the World Wide Web (WWW) for accessing requested information. Many ILL departments are already committed to using one of the library-to-library distribution systems mentioned above. Getting the documents out of those systems and on to the WWW requires additional software. As reported by Schnell, Doc Morph, Web-EDD, Prospero, and EDD (Yale University) are all iterations of software used to transform a document from a library-to-library transmission system and place the document on a server for access via the WWW (Schnell, 1999).

\section{Copyright}

When the PHSL administration requested the investigation of document delivery to the computer desktop, they also required that, whatever method was adopted, it must meet all established guidelines for fair use and copyright. The Digital Millennium Copyright Act (DMCA) had just been enacted. In reviewing library, computer science, and law literature, no conclusive statements or consensus could be found on how copyright infringement would be defined in a digital environment. Reports by libraries on desktop document delivery did not address copyright issues. Gasaway summarized DMCA and the related Ashcroft and BoucherCampbell bills by stating, "Under both bills, the fair use provision of the Act would be expanded to make it clear that fair use applies also to works in digital format and in the networked environment" (Gasaway, 1998). Many articles indicated that it is not yet known or defined how copyright would be applied to electronic document delivery (Tennant, 1999; Eiblum/Ardito, 1999; Cornish, 1998).

One article suggested that as electronic services develop, copyright law might move toward contract law between publishers and libraries (Russon/Campbell, 1996). A number of articles did state that since copyright law is technologically neutral it is permissible for a library to make an electronic copy (Heller, 1996; Litman, 2000). No research in this literature review ever indicated that the electronic distribution of documents would infringe or not comply with copyright law.

\section{THE INVESTIGATION}

In early 1999, the Head of Document Delivery and I discussed the process for testing desktop delivery and paperless processing. We agreed to the following plan:

1. We would limit initial testing to materials that are borrowed, since we receive $80 \%$ of ILL document requests through Ariel.

2. We would investigate delivery of documents as email attachments. 
3. We would decide on the delivery method first, before examining internal procedures to meet our goal of paperless processing.

\section{Phase 1: Ariel Email}

Ariel software contains programming that allows for received documents to be attached as email messages and sent to the client. Since Ariel documents are transmitted in Text Image File Format (TIFF), we contacted the PHSL Information Technology (IT) Department and asked to have a TIFF viewer installed on a workstation. IT staff recommended that we not pursue this line of investigation for the following reasons:

1. TIFF viewers are not the norm at OSU;

2. TIFF readers sometimes have problems reading multi-page documents and displaying graphics;

3. TIFF files can be manipulated and therefore documents under copyright might be vulnerable to infringement.

After further consultation with IT staff, they recommended we purchase Adobe Acrobat Exchange software to convert TIFF transmitted documents into Portable Document Format (PDF).

\section{Phase 2: Adobe Acrobat Exchange}

IT installed Exchange on the computer used for Ariel transmission. We selected ten documents received via Ariel that ranged in size from 6 p. (301 kb) to $15 \mathrm{p}$. $(2803 \mathrm{~kb})$. The documents were sent through the Exchange program and saved in a folder on the workstation hard drive. An email message was crafted and the PDF attached. The results were successful. All messages were received and the attached PDF files opened. This proved to be a realistic option except for two processing concerns:

1. The conversion process from TIFF to PDF was very slow, especially for large articles;

2. Extra steps were required to save the PDF to disk and attach the document.

These concerns led us to realize there would be no saving of processing time for staff. The following additional concerns were added to our list after consultation with IT staff:

1. Multiple email platforms used by our clients may impact access due to email attachment size limitations;

2. Clients may lose the document if the message is deleted from the email server;

3. Myriad Internet connection options may impact the speed of opening attached documents;

4. Clients may have connectivity questions that are beyond the scope of Document Delivery staff to solve. 
These concerns caused us to abandon email attachments as a viable option for providing desktop delivery. After further consultation with IT staff, a new plan developed. IT staff would provide a program that (1) interfaced with Ariel, (2) contained a file of client email addresses, (3) converted TIFF to PDF, (4) placed the document on a server, and (5) sent an email message with document url to inform clients the requested item could be retrieved.

\section{Phase 3: PDF/Web Access}

While this program was developed, the Head of Document Delivery and I planned the patron interface web page and pilot test. We would create a test web site containing a simple web request form using Microsoft Front Page. (See Appendix I.) The form required two levels of programming. In level one, Perl scripts were used to manage the form response to the client. If a required field was not completed, the interface informed the client to fill in the missing information. Level two programming, also Perl scripts, sent a response back to the client and forwarded the request to a Microsoft Outlook mailbox on the ILL workstation in the Document Delivery Unit. (See Appendix II.) We chose Microsoft Outlook to manage incoming requests because the message is easily edited. All searching, ordering, copyright, receiving, and any other tracking information is added to each request. When the document is received, the original request is edited to show receipt and archived in a "completed" monthly folder.

The last issue to investigate was how to inform our clients that copyright law might apply. Under the DMCA, libraries must now include a copyright statement with any requested material. Our concerns were what to do if we did not receive this information with the requested document from another library and, how to educate our clients that their electronically received document should not be manipulated. To support copyright compliance, we decided on the following: (1) add a copyright compliance page during the client request process (See Appendix III.), (2) add a copyright notice that would automatically be inserted as the first page of each document, and (3) program the server module to deny access after five viewings or delete the document after two weeks.

The above decisions were based on The American Association of Law Librarians (AALL) guidelines on the fair use of works under copyright. These guidelines cover the reproduction, distribution, and display of copyrighted works, whether published in print or available in digital format, and whether the copying is analog (i.e., photocopying or microform) or electronic (i.e., scanning). It also states that ILL departments must not keep a copy of any borrowed material whether in print or digital. The guidelines include a recommendation that, besides the actual copyright notice, the following additional statement should be added: No further reproduction and distribution of this copy is permitted by transmission or any other means (AALL, 1999).

In July 1999, the above information, along with the url for our test Web site, was sent to The OSU Office of Legal Affairs, which reviewed the entire service and responded with the following opinion. Because the digital aspects of the service were at that time new territory and, sections 107 and 108 of copyright law can be interpreted quite differently by libraries, users, publishers, and copyright holders, we were advised to add the following steps to our process:

1. Destroy any original paper or digital copy.

2. Add the statement, "No further reproduction and distribution of this copy is permitted 
by transmission or any other means." This notice should appear on the initial retrieval screen and on the initial copyright notice screen preceding the Adobe document itself.

3. Keep exploring the implementation of additional technical methods to prohibit the user from transmitting or copying the document.

4. Keep investigating whether additional guidelines or "best practices" are developed and if an industry standard should emerge, adopt such standards.

Implementation of these recommendations occurred in August 1999 and preparations for the pilot test were finalized. The program developed by IT staff was completed and would be called Prospero. The pilot test would be called 3D or Document Delivery to the Desktop.

\section{PILOT TEST: PART ONE}

The pilot test was divided into two parts. During the first six months, test participants included members of the COMPH Library Committee plus five selected staff. These twenty individuals represented all categories of our primary clientele. We added their names and email addresses to the Prospero user file. In keeping with an all-electronic theme, instructions for use were sent via email to all participants. The goals were to solve technical problems, ascertain quality of articles, and make suggestions or corrections to the overall process.

Between October and December 1999, forty-six requests were received. Twenty-five were rejected upon receipt. The high rejection rate stemmed from a lack of understanding by participants that requests should be for materials not available on campus. In all cases a standard letter was sent informing the patron of the on campus location and call number.

\section{Results of the First Six Months}

\begin{tabular}{|c|c|c|c|c|}
\hline Participants & Total Requests & Rejects & Remaining Requests & Problems \\
\hline 20 & 46 & 25 or $54.3 \%$ & 21 & 11 or $52.38 \%$ \\
\hline
\end{tabular}

The remaining twenty-one requests were processed and problems categorized into three groups: (1) erroneous information supplied by client, (2) processing problems, and (3) access issues. Group 1 had three requests (14.28\%) because the clients submitted invalid email addresses. Clients were notified and submitted the correct address. Processing problems yielded two requests (9.52\%). These had to be processed a second time because of Ariel-receipt problems from the loaning library. And finally, six problems (28.57\%) were access problems: (1) Two clients didn't have the correct version of Acrobat Reader; (2) One client had a browser manager that prohibited access; (3) One client received a blank document; (4) One client received the message "Invalid user name or pin" when trying to access the document; (5) And lastly, one client did not have a compatible version of Netscape. Document Delivery staff solved the first two groups of problems. Access problems were forwarded to IT staff for resolution.

In January 2000, we emailed our test participants a brief survey. Of the 20 surveys sent, 
11 or $55 \%$ were returned. The survey questions were:

1. Did you receive the correct article with all of the pages?

2. Was the scanned article readable/useable? Or how was the quality?

3. Were there any problems with requesting, receiving, or opening the article?

4. Do you have any comments on the request form web page?

5. Do you have any comments on the notification process (email message) or logging in to the 3D service?

6. For our information, would you be willing to pay a minimal charge for this service, such as $\$ 3.00$ per article?

7. Do you have any other suggestions or comments about 3D?

\section{Survey Results}

\begin{tabular}{|l|c|c|}
\hline \multicolumn{2}{|c|}{ Positive Response } & Negative Response \\
\hline Question 1: & 11 & 0 \\
\hline Question 2: & 10 & 1 \\
\hline Question 3: & 3 & 8 \\
\hline Question 4: & 1 & 10 \\
\hline Question 5: & 0 & 11 \\
\hline Question 6: & 0 & 11 \\
\hline Question 7: & 0 & 11 \\
\hline
\end{tabular}

The negative response to question two was due to a number of pages being upside down. Participants with incorrect browser or Acrobat Reader versions responded negatively to question three. In response to question number four, a client suggested we add a box on the web request form to allow for the insertion of a full citation cut and pasted from another research tool, i.e., Medline. Comments received from question seven indicated that the new service was excellent and greatly appreciated.

\section{PILOT TEST: PART TWO}

Part one of the pilot test pinpointed a number of problems that were solved and the test participants' response was enthusiastic so preparations were made to go forward with testing. The goals were to increase the number of users, finalize the web request form, and realize paperless processing.

To increase the number of users, we offered the option of electronic delivery to clients when they were notified that their documents had arrived. We also sent them the instructions and URL for using the service in the future. Over the next six months, the client database grew to over sixty users. There were no new processing problems identified with this increased activity.

We made one major change, identified by a client during pilot test part one, and added a text box to the request form, which allows a client to cut and paste the citation from a research database. (See Appendix IV.) The addition of this feature was very popular with our users. We also began seeing a new problem. Certain characters within citations prevented the request from 
being submitted. There were approximately four of these and each case was easily resolved by programming changes to the web request form.

Our final goal, paperless processing, was realized with the ILL borrowing requests. ILL processing now consists of the following steps:

1. Requests must be made electronically.

2. Requests received are searched and ordered electronically.

3. Requests received via Ariel are transmitted through Prospero to the client.

a. Requests received in paper are scanned into Prospero and forwarded to the client.

4. Receipt and disposition is noted on the original electronic request.

5. Requests are archived to floppy disk each month.

6. Floppy disks are stored for statistics and audit purposes.

Although we still receive some photocopies from other libraries, these are not "our" paper. Documents received in a paper format are about $15 \%$ of our total ILL borrowing process.

\section{CONCLUSIONS}

The results of desktop document delivery were deemed a success. In October 2000, electronic delivery of documents was offered as a regular delivery method. We revised all appropriate web forms on the PHSL web site. One week prior to full implementation, we announced the service via email to all faculty, staff, and students in the Health Sciences Center. We inserted announcements in various newsletters and also with documents still being mailed or picked up. All announcements included instructions for using the service. By March 2001, 85$90 \%$ of all requested documents were being electronically delivered. We did not implement a fee for this new service.

The results of paperless processing are still mixed. By definition, the ILL process for borrowing is now paperless. We have yet to make the lending process paperless because we have not yet found a method to electronically copy the request in order to go to the stacks to pull the requested item. Initial plans are being developed to see if a Personal Digital Assistant (PDA) can be utilized to synch requests into an electronic format for material retrieval. By scanning directly from the item using a Minolta PS3000, we have eliminated photocopying the document prior to scanning for delivery.

We continue to identify and investigate methods to make this process more efficient and convenient for both clients and PHSL staff. We also hope to enlarge this service to meet the needs of OSU distance education programs and other initiatives.

\section{REFERENCES}

American Association of Law Librarians. (1999). AALL guidelines on the fair use of copyrighted works by Law Libraries. Retrieved January 28, 2000 from the World Wide Web: http://www.aallnet.org/about/policy_fair.asp.

Cornish, Alan. (2000). The Relais document delivery system: an innovative model for resources sharing. Journal of Interlibrary Loan, Document Delivery \& Information Supply, 10 (3), 77-84.

Cornish, Graham P. (1998). Copyright and document delivery in the electronic environment. Interlending \& Document Supply, 25 (3), 123-129. 
Eiblum, Paula, \& Ardito, Stephanie C. (1999). Document delivery \& copyright: librarians take the fifth. Online, September/October, 73-76.

Gasaway, Laura N. (1998). Copyright, the Internet, and other legal issues. Journal of the American Society for Information Science, 49 (11), 1003-1009.

Heller, James S. (1996). The Impact of recent litigation on interlibrary loan and document delivery. Law Library Journal, 88 (1) winter, 158-177.

Litman, Jessica. (1996). First Monday: copyright law and electronic access to information. Retrieved February 15, 2000 from the World Wide Web: http://www.firstmonday.dk/ issues/issue4/litman/.

Russon, David, \& Campbell, Robert. (1996). Access to journals: a joint publisher/librarian analysis. Logos, 7 (2), 178-185.

Schnell, Eric H. (1999). Freeing Ariel: the Prospero electronic document delivery project. Journal of Interlibrary Loan, Document Delivery \& Information Supply, 10 (2), 89-100.

Shipman, Jean P. et al. (1998). Desktop document delivery using portable document format (PDF) files and the Web. Bulletin of the Medical Library Association, 86 (3) July 307-315.

Tennant, Roy. (1999). Copyright and intellectual property rights. Library Journal, 124 (13) August 34-36.

\section{APPENDIX I}

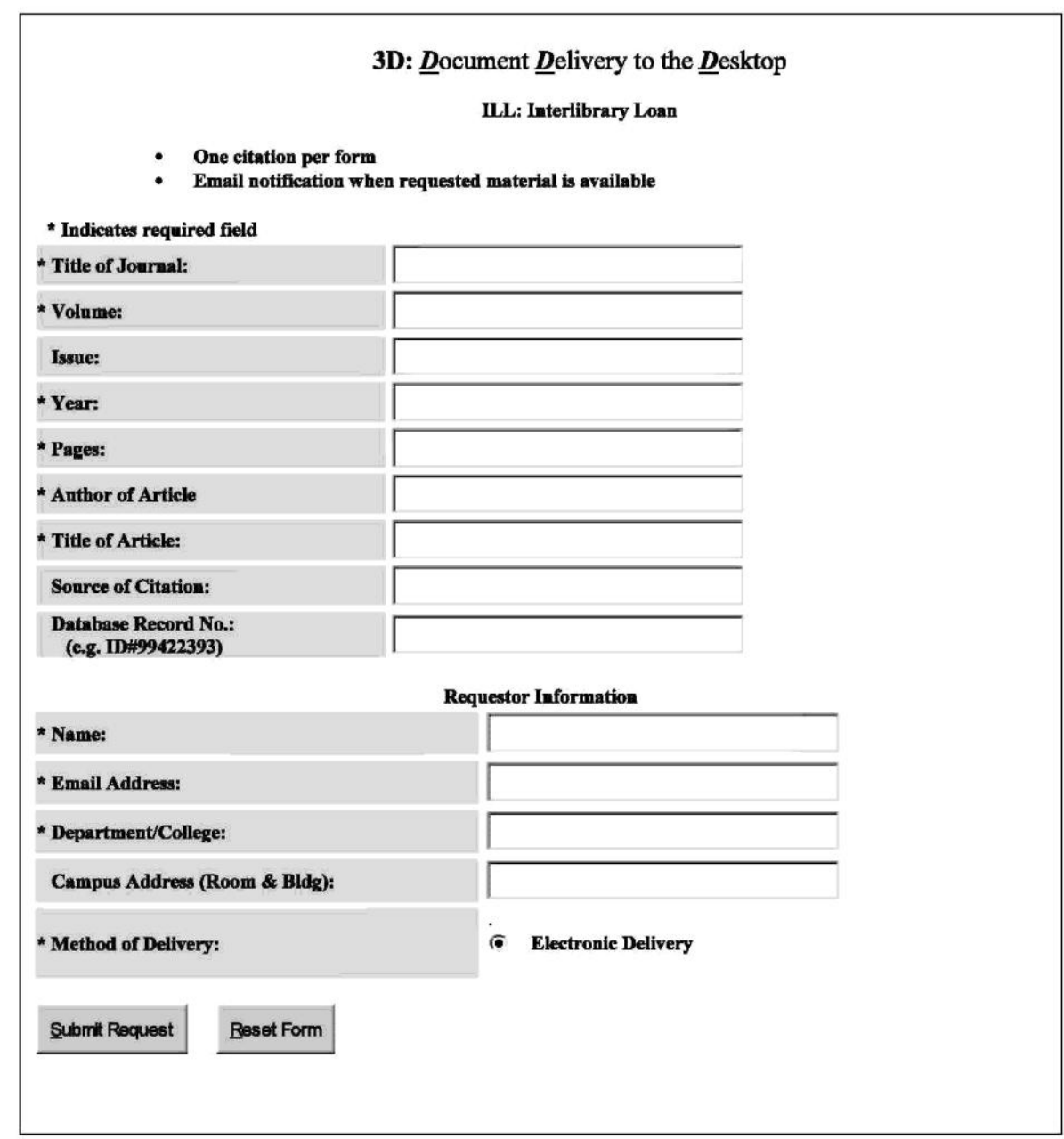




\section{APPENDIX II}

\section{Interface Response to Client for Missing Information}

\begin{tabular}{|l|}
\hline \multicolumn{1}{|c|}{ 3D: $\underline{D}$ ocument $\underline{D}$ elivery to the $\underline{D}$ esktop } \\
We require that certain fields are filled in to complete a request. You must fill in the \\
following fields that were left blank: \\
Volume \\
Year \\
Pages \\
Author of Article \\
Title of Article \\
Your Name \\
Email Address \\
Department/College \\
Return to form \\
\hline
\end{tabular}

\section{Verification Notice for Client}

\begin{tabular}{|c|c|}
\hline The following & $\begin{array}{l}\text { 3D: } \underline{\text { Docum }} \\
\text { g has been sent to The }\end{array}$ \\
\hline Title of Journal & test \\
\hline Volume & test \\
\hline Year & test \\
\hline Pages & test \\
\hline Author of Article & test \\
\hline Title of Article & test \\
\hline Source of Ref & Medline \\
\hline Database Record No. & 992233441 \\
\hline Your Name & Ruey Rodman \\
\hline Department/College & Library \\
\hline Email Address & rodman.1@osu.edu \\
\hline Campus Address & 220 Prior \\
\hline Delivery Method & Electronic Delivery \\
\hline Return to 3D & \\
\hline
\end{tabular}




\section{APPENDIX III}

\section{D: $\underline{D}$ ocument $\underline{D}$ elivery to the $\underline{D}$ esktop}

\section{Interlibrary Loan: Document Delivery Request Summary}

If the following information is correct, please read the Copyright Compliance statement at the bottom of the page before submitting request. Click here to make corrections.

Title of Journal $=$ test

Volume $=$ test

Year $=$ test

Year $=$ test
Pages $=$ test

Author of Article $=$ test

Title of Article $=$ test

Source of $\operatorname{Ref}=$ test

Database Record No. $=$ test

Your Name $=$ Ruey Rodman

Department/College $=$ Library

Email Address = rodman.1@ @osu.cdu

Campus Address = 220 Prior

Delivery Method $=$ Electronic Delivery

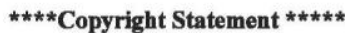

No further reproduction and distribution of this copy is permitted by transmission or any other means.

The user should review the copyright notice from the original work that will be included with the requested electronic copy.

Section 108: United States Copyright Law

The copyright law of the United States (Title 17, United States Code) governs the making of

photocopies or other reproductions of copyrighted material. Under certain conditions specified in the law, libraries and archives are authorized to furnish a photocopy or other reproduction. One of these specified conditions is that the photocopy or reproduction is not to be "used for any purpose other than private study, scholarship, or research." If a user makes a request for, or later uses, a photocopy or reproduction for purposes in excess of "fair use," that user may be liable for copyright infringement.

This institution reserves the right to refuse to accept a copying order, if, in its judgment, fulfillment of the order would involve violation of copyright law.

I Agree, Please Submit Request 


\section{APPENDIX IV}

\section{Revised Web Request Form}

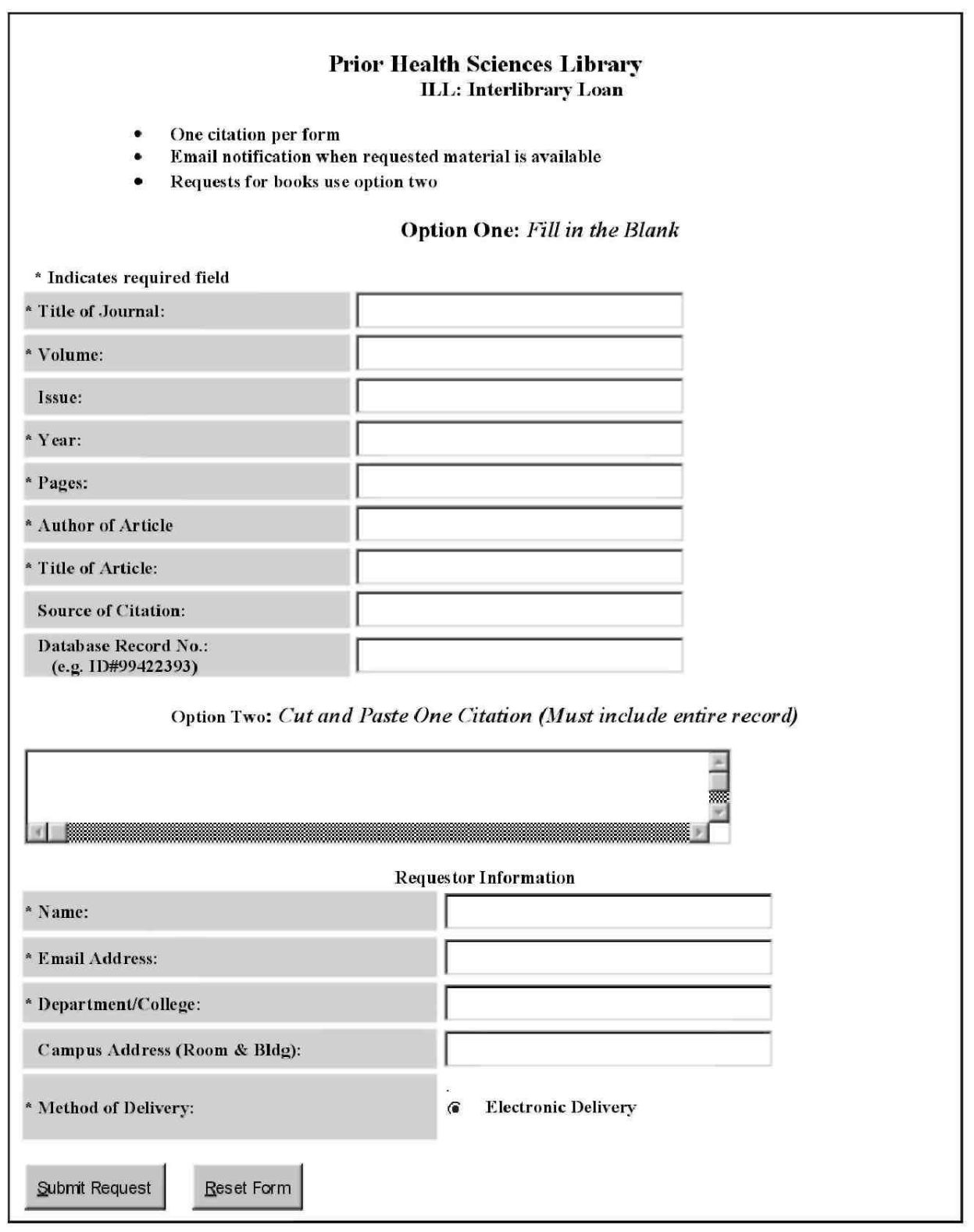

